\title{
Alcohol use and misuse among school adolescents from national surveys in Saint Lucia and Saint Vincent and the Grenadines in 2018
}

Karl Peltzer ( $\boldsymbol{\sim}$ kfpeltzer@gmail.com )

Asia University

\section{Supa Pengpid}

Mahidol University

\section{Research Article}

Keywords: alcohol use, mental health, adolescents, Saint Lucia, Saint Vincent and the Grenadines

Posted Date: September 14th, 2021

DOI: https://doi.org/10.21203/rs.3.rs-899663/v1

License: (c) (i) This work is licensed under a Creative Commons Attribution 4.0 International License.

Read Full License 


\section{Abstract}

The study aimed to estimate the prevalence of alcohol use and misuse and associated factors among adolescents in Saint Lucia and Saint Vincent and the Grenadines. Data from 3,847 adolescents (mean age:14.6 years, $S D=1.7$ ) that took part in national cross-sectional school surveys in 2018 in Saint Lucia, and Saint Vincent and the Grenadines were analysed. Students responded in a classroom setting to selfadministered questions on substance use and othe variables. The results indicate that $42.7 \%$ of the students reported current alcohol use, $27.9 \%$ were ever drunk and $11.4 \%$ had trouble with alcohol use. In adjusted logistic regression analyses, compared to students from Saint Lucia, students from Saint Vincent and the Granadines had higher odds of trouble from drinking. Older age was associated with current alcohol use and ever drunk but not with trouble from drinking. Severe food insecurity and suicidal ideation were associated with trouble from alcohol use. Current tobacco use and current cannabis use were highly associated with current alcohol use, ever drunk, and trouble with alcohol use, while ever use of amphetamines was associated with ever drunk. School truancy, participation in physical fights, injury, and multiple sexual partners increased the odds, while parental support decreased the odds of current alcohol use, ever drunk, and trouble from alcohol use. In conclusion, high alcohol use and misuse has been identified calling for interventions.

\section{Introduction}

Alcohol use contributes significantly to morbidity and mortality, globally (GBD 2016 Alcohol Collaborators, 2018), and is increasing among adolescents (Mokdad et al., 2016). Exposure to alcohol use during adolescence can increase the risk of developing alcohol use problems later in life (Nixon \& McClain, 2010). Globally, among adolescents in low- and middle-income countries, $25.0 \%$ used alcohol in the past month, 17.6\% had ever been drunk, and 10.6\% had trouble from drinking (Ma et al., 2018). Among adolescents in six Caribbean countries the prevalence current alcohol use ( $\geq 3$ days in past month) was 20.7\% (Peltzer \& Pengpid, 2015), and in four Caribbean countries (Dominican Republic, Suriname, Jamaica, and Trinidad and Tobago), the proportion of ever drunk was $28.6 \%$, and trouble from alcohol use 11.9\% (Pengpid \& Peltzer, 2021). In 2007, the prevalence of current alcohol in two Caribbean countries, Saint Lucia and Saint Vincent and the Grenadines, were high, $55.8 \%$ and $56.4 \%$, respectively (Balogun et al., 2014). There is a lack of newer data on alcohol use and misuse and its correlates in Saint Lucia and Saint Vincent and the Grenadines, which led to the study.

Factors associated with alcohol use and misuse among adolescents consist of sociodemographic (male sex and older age), psychological (distress and other substance use), social problem (truancy, interpersonal violence, and injury and social support (peers and/or parents) variables (Pengpid \& Peltzer, 2019). In order to better target interventions on alcohol use among adolescents, it is important to assess the current prevalence and correlates. The study aimed to estimate the prevalence of alcohol use and misuse and associated factors among in-school adolescents in Saint Lucia and Saint Vincent and the Grenadines in 2018. 


\section{Methods}

\section{Study design and participants}

Data from 1,877 adolescents that participated in the cross-sectional national Global School-based Student Health Survey (GSHS) in Saint Lucia (77\% response rate), and Saint Vincent and the Granadines (78\% response rate) in 2018 were analysed (WHO, 2021). Details of the GSHS and the data set can be accessed (WHO, 2021). Briefly, "using a two-stage cluster sampling strategy (schools were selected by probability to size sampling and random selection of class rooms with students 13 to 17 years of age), a nationally representative sample of middle school students was produced." (WHO, 2021). "All students who attended a selected class were eligible to participate, regardless of their age, and completed a selfadministered questionnaire in their language under the supervision of trained external survey administrators." (WHO, 2021). A national ethics committee provided ethics approval and written informed consent was obtained from participants (WHO, 2021).

\section{Measures}

Details of the GSHS measure used in this study are provided in Appendix 1. Sociodemographic variables included age, sex and food insecurity. Psychological variables consisted of having no close friends, anxiety, loneliness, suicidal ideation, suicide plan, suicide attempt, current tobacco use, current cannabis use and ever use of amphetamines. Social variables included school truancy, physical assault, participation in physical fights, physical injury, multiple sexual partners, and non-condom use. Social support variables included, parental support and peer support. Parental support items were summed, and classified into: "0-1 low, 2 medium and 3-4 high support."

\section{Data analysis}

Sample characteristics are shown using descriptive statistics. Simple and multiple logistic regressions were used to assess associations between sociodemographic, psychological, social problem, social support variables and alcohol use and misuse variables (current alcohol use, ever drunk and trouble from alcohol use). Missing cases were excluded from the analysis. $\mathrm{P}<0.01$ was considered significant. All statistical procedures were performed using the "STATA software version 15.0 (Stata Corporation, College Station, Texas, USA), by taking into account sampling weighting and complex study design.

\section{Results}

\section{Sample characteristics}

The sample consisted of 3,847 school adolescents (mean age:14.6 years, SD=1.7) from Saint Lucia, and Saint Vincent and the Grenadines. More than half of the participants (51.1\%) were females, $52.8 \%$ had moderate or severe food insecurity, $25.3 \%$ had high peer support and $53.4 \%$ had moerate or high parental support. In total, $42.7 \%$ of students reported current alcohol use, $27.9 \%$ ever drunk, and $11.4 \%$ trouble from alcohol use. Among students who were current alcohol users in Saint Vincent and the Granadines 
the most frequent source of alcohol was "I got it from my family" (34.6\%) and "I bought in a store" (17.6\%), while in Saint Lucia the most frequent source of alcohol was "I got it from my friends (31.1\%) and "I bought in a store" (24.7\%). Female students more often sourced alcohol from the family (35.8\%) than male students $(22.1 \%)$, and male students more often sourced alcohol from buying in the shop (24.6\%) than female students (15.2\%). Further sample details are provided in Table 1 (see Table 1).

\section{Simple logistic regression with alcohol use outcomes}

Compared to Saint Lucia students, Saint Vincent and the Granadines students had higher odds of ever being drunk and troubled by drinking, and male sex was associated with ever being drunk and troubled by drinking, and older age and food insecurity increased the odds of current alcohol use, ever being drunk and trouble from alcohol use. Apart from having no close friends, all other psychological problem variables (loneliness, anxiety, suicidal behaviour, and other substance) were associated with current alcohol use, ever drunk and trouble from alcohol use. Similarly, all social problem variables (truancy, interpersonal violence, injury and sexual risk behaviour) were associated with current alcohol use, ever drunk and trouble from alcohol use. Regarding social support, peer support was not associated with alcohol use variables, and high parental support was protective against current alcohol use, ever drunk and trouble from alcohol use (see Table 2).

\section{Multiple logistic regression with alcohol use outcomes}

In adjusted logistic regression analyses, compared to students from Saint Lucia, students from Saint Vincent and the Granadines had higher odds of trouble from drinking. Older age was associated with current alcohol use and ever drunk but not with trouble from drinking. Severe food insecurity and suicidal ideation were associated with trouble from alcohol use. Current tobacco use and current cannabis use were highly associated with current alcohol use, ever drunk, and trouble from alcohol use, while ever use of amphetamines was associated with ever drunk. School truancy, involvement in physical fighting, injury and multiple sexual partners increased the odds, while parental support decreased the odds of current alcohol use, ever drunk, and trouble from alcohol use (see Table 3).

\section{Discussion}

The goal of this investigation was estimated the extent of alcohol use and its correlates among in-school adolescents in Saint Lucia and Saint Vincent and the Grenadines in the 2018. A high prevalence of current alcohol use (42.7\%) was found, higher than globally in low- and middle-income countries (25.0\%) (Ma et al., 2018) and in six Caribbean countries (20.7\%) (Peltzer \& Pengpid, 2015), but lower than in the 2007 surveys in Saint Lucia and Saint Vincent and the Grenadines (55.8\% and 56.4\%, respectively) (Balogun et al., 2014). The prevalence of ever drunk (27.9\%) was similar to four Caribbean countries (Dominican Republic, Suriname, Jamaica, and Trinidad and Tobago) (28.6\%), but higher than in low- and middle-income countries (17.6\%) (Ma et al., 2018), and from alcohol use (11.4\%) was similar to the four Caribbean countries (11.9\%) (Pengpid \& Peltzer, 2021), and globally in low- and middle-income countries (10.6\%) (Ma et al., 2018). It is possible that a strengthening of the health family life education 
programme contributed to the reduction in current alcohol use in Saint Lucia and Saint Vincent and the Grenadines.

Unlike some previous studies (Ma et al., 2018, Peltzer et al., 2016), we did not find significant gender differences in the prevalence of current alcohol, only problem drinking was significantly higher among boys than girls, as found in former research (Ma et al., 2018, Peltzer et al., 2016). It seems that social and cultural norms in the Caribbean allow females to engage in drinking (Japal \& Oliver, 2017). This seems to be confirmed by our study results that female students most commonly sourced alcohol from the family (35.8\%) and from buying in the shop (24.6\%). In a review of adolescents in Latin America and the Caribbean, alcohol was also most commonly obtained from home (Probst et al., 2018). This trend of females engaging in drinking may also be reinforced by alcohol marketing strategies (Ma et al., 2018). According to previous research (Darteh, 2021; Ma et al., 2018), the prevalence of current alcohol use and ever drunk increased with age, which can be attributed to better access to alcohol and greater role of peer influence in later adolescence.

In consistence with previous research (Balogun et al., 2019; Darteh, 2021; Pengpid \& Peltzer, 2019), we found an association between psychological problems (suicidal ideation and other substance use, including current tobacco use, current cannabis use and ever amphetamine use) and current alcohol use, ever drunk and/or trouble from drinking. Furthermore, several social problems (school truancy, interpersonal violence and injury, and having multiple sexual partners) were found associated with alcohol use and misuse in this study. These findings concur with former research (Peltzer et al., 2016;

Asante, \& Kugbey, 2019). Students may try to cope with stressful situations by drinking alcohol (Page, 2011), and seem to engage in multiple health risk behaviours that respond to social and psychological functions in adolescence, such as individuation from parents and trying to achieve adult status (Jessor \& Jessor, 1997).

While some research found an association between lack of peer support (Asante \& Kugbey, 2019) and alcohol use and misuse in adolescents, we did not find such an association. May be is is because overall peer support was found to be low, only $25.3 \%$ had high peer support. Consistent with other research (Darteh 2021; Peltzer et al., 2016), we found that higher parental support was protective against alcohol use and misuse. Parental support may be utilized in programmes targeting alcohol problems among adolescents.

\section{Study Limitations}

"Secondary education net-enrolment ratio" was 80.4\% in Saint Lucia im 2018, and 89.5\% in Saint Vincent and the Granadines in 2018 (UNESCO, 2019a, 2019b), which means some out-off school adolescents were excluded from this study. Due to the cross-sectional design, we cannot make causal inferences. Some variables, such as parental alcohol use, were not assessed, and should be part of future research. Data were collected by self-report, which may have led to under or overreporting of some variables. 


\section{Conclusions}

High alcohol use and misuse was identified. Several factors associated with current alcohol use, ever drunk and/or trouble from alcohol use were found, including country, older age, severe food insecurity, suicidal ideation, other substance use, school truancy, physical fighting, injury, multiple sexual partners and lack of parental support, allof which can be targeted in interventions.

\section{Declarations}

\section{Acknowledgements}

"The data source, the World Health Organization NCD Microdata Repository (URL:

https://extranet.who.int/ncdsmicrodata/index.php/catalog), is hereby acknowledged."

Competing interests: The authors declare no competing interests.

\section{References}

Asante, K.O., \& Kugbey, N. (2019). Alcohol use by school-going adolescents in Ghana: Prevalence and correlates. Mental Health \& Prevention, 13, 75-81.

Balogun, O., Koyanagi, A., Stickley, A., Gilmour, S., \& Shibuya, K. (2014). Alcohol consumption and psychological distress in adolescents: a multi-country study. The Journal of Adolescent Health, 54(2), 228-234. https://doi.org/10.1016/j.jadohealth.2013.07.034

Balogun, O., Koyanagi, A., Stickley, A., Gilmour, S., \& Shibuya, K. (2014). Alcohol consumption and psychological distress in adolescents: a multi-country study. The Journal of adolescent health: official publication of the Society for Adolescent Medicine, 54(2), 228-234.

https://doi.org/10.1016/j.jadohealth.2013.07.034

Darteh, E. K. M. (2021). Alcohol use among school-going adolescents in Mozambique: prevalence and correlates. Journal of Substance Use. DOI: 10.1080/14659891.2021.1916843

GBD 2016 Alcohol Collaborators (2018). Alcohol use and burden for 195 countries and territories, 19902016: a systematic analysis for the Global Burden of Disease Study 2016. Lancet, 392(10152), 10151035. https://doi.org/10.1016/S0140-6736(18)31310-2

Japal, E., \& Oliver, B. (2017). A sociological perspective of alcohol use in the Caribbean. International Public Health Journakbi >,</bi> 9(1), 7-9.

Jessor, R., \& Jessor, S. (1997). Problem Behaviour and Psychosocial Development: A Longitudinal Study of Youth; Academic Press: New York, NY, USA, 1997. 
Ma, C., Bovet, P., Yang, L., Zhao, M., Liang, Y., \& Xi, B. (2018). Alcohol use among young adolescents in low-income and middle-income countries: a population-based study. The Lancet. Child \& Adolescent Health, 2(6), 415-429. https://doi.org/10.1016/S2352-4642(18)30112-3

Mokdad, A. H., Forouzanfar, M. H., Daoud, F., Mokdad, A. A., El Bcheraoui, C., Moradi-Lakeh, M., Kyu, H. H., Barber, R. M., Wagner, J., Cercy, K., Kravitz, H., Coggeshall, M., Chew, A., O'Rourke, K. F., Steiner, C., Tuffaha, M., Charara, R., Al-Ghamdi, E. A., Adi, Y., Afifi, R. A., ... Murray, C. J. (2016). Global burden of diseases, injuries, and risk factors for young people's health during 1990-2013: a systematic analysis for the Global Burden of Disease Study 2013. Lancet, 387(10036), 2383-2401. https://doi.org/10.1016/S01406736(16)00648-6

Nixon, K., \& McClain, J. A. (2010). Adolescence as a critical window for developing an alcohol use disorder: current findings in neuroscience. Current Opinion in Psychiatry, 23(3), 227-232. https://doi.org/10.1097/YC0.0b013e32833864fe

Page, R. M., Dennis, M., Lindsay, G. B., \& Merrill, R. M. (2011). Psychosocial distress and substance use among adolescents in four countries: Philippines, China, Chile, and Namibia. Youth and Society, 43, 900930.

Peltzer, K., \& Pengpid, S. (2015). Early Sexual Debut and Associated Factors among In-school Adolescents in Six Caribbean Countries. The West Indian Medical Journal, 64(4), 351-356. https://doi.org/10.7727/wimj.2014.025

Peltzer, K., Pengpid, S., \& Tepirou, C. (2016). Associations of alcohol use with mental health and alcohol exposure among school-going students in Cambodia. Nagoya Journal of Medical Science, 78(4), 415422. https://doi.org/10.18999/nagjms.78.4.415

Pengpid, S., \& Peltzer, K. (2019). Alcohol Use and Misuse Among School-Going Adolescents in Thailand: Results of a National Survey in 2015. International Journal of Environmental Research and Public Health, 16(11), 1898. https://doi.org/10.3390/ijerph16111898

Pengpid, S., \& Peltzer, K. (2021). Multiple behavioural risk factors of non-communicable diseases among adolescents in four Caribbean countries: prevalence and correlates. International journal of adolescent medicine and health, 10.1515/ijamh-2021-0021. Advance online publication.

https://doi.org/10.1515/ijamh-2021-0021

Pengpid, S., \& Peltzer, K. (2021). Prevalence and associated factors of psychological distress among national samples of in-school adolescents in four Caribbean countries. Vulnerable Children and Youth Studies, DOI: 10.1080/17450128.2021.1896825

Probst, C., Monteiro, M., Smith, B., Caixeta, R., Merey, A., \& Rehm, J. (2018). Alcohol Policy Relevant Indicators and Alcohol Use Among Adolescents in Latin America and the Caribbean. Journal of Studies on Alcohol and Drugs, 79(1), 49-57. 
UNESCO (2019a). Participation in education, Saint Lucia. URL: http://uis.unesco.org/en/country/lc (accessed 2 Sept 2021).

UNESCO (2019b). Participation in education, Saint Vincent and the Granadines. URL: http://uis.unesco.org/en/country/vc (accessed 2 Sept 2021).

UNICEF (2009) Strengthening health and family life education in the region: the implementation, monitoring, and evaluation of HFLE in four CARICOM countries. URL:

https://healtheducationresources.unesco.org/library/documents/strengthening-health-and-family-lifeeducation-region-implementation-monitoring-0 (accessed 11 Sept 2021)

World Health Organization (WHO) (2021). Global school-based student health survey (GSHS). URL: <background-color:\#FF3300;bu>https://www.who.int/ncds/surveillance/gshs/en/</backgroundcolor:\#FF3300;bu> (accessed 20 Mar 2021)

\section{Tables}

Table 1: Sample characteristics by alc00ohol use type 


\begin{tabular}{|c|c|c|c|c|}
\hline Variable & Sample & $\begin{array}{l}\text { Current alcohol } \\
\text { use }\end{array}$ & $\begin{array}{l}\text { Ever } \\
\text { drunk }\end{array}$ & $\begin{array}{l}\text { Trouble from } \\
\text { drinking }\end{array}$ \\
\hline & $\mathrm{N}(\%)$ & $\%$ & $\%$ & $\%$ \\
\hline \multicolumn{5}{|l|}{ Socio-demographics } \\
\hline All & 3847 & 47.2 & 27.9 & 11.4 \\
\hline \multicolumn{5}{|l|}{ Country } \\
\hline Saint Lucia & $\begin{array}{l}1970 \\
(51.2)\end{array}$ & \multirow{2}{*}{$\begin{array}{l}47.1 \\
47.5\end{array}$} & \multirow{2}{*}{$\begin{array}{l}24.9 \\
34.5\end{array}$} & \multirow{2}{*}{$\begin{array}{l}9.7 \\
15.3\end{array}$} \\
\hline Saint Vincent/Grenadines & $\begin{array}{l}1877 \\
(48.4)\end{array}$ & & & \\
\hline \multicolumn{5}{|l|}{ Age (years) } \\
\hline$\leq 13$ & $841(28.0)$ & 34.8 & 15.5 & 8.2 \\
\hline $14-15$ & $\begin{array}{l}1589 \\
(37.9)\end{array}$ & \multirow{2}{*}{$\begin{array}{l}44.8 \\
59.5\end{array}$} & \multirow{2}{*}{$\begin{array}{l}24.3 \\
41.5\end{array}$} & \multirow{2}{*}{$\begin{array}{l}11.2 \\
14.1\end{array}$} \\
\hline$\geq 16$ & $\begin{array}{l}1400 \\
(34.1)\end{array}$ & & & \\
\hline \multicolumn{5}{|l|}{ Gender } \\
\hline Female & $\begin{array}{l}2026 \\
(51.8)\end{array}$ & \multirow{2}{*}{$\begin{array}{l}47.1 \\
47.5\end{array}$} & \multirow{2}{*}{$\begin{array}{l}24.2 \\
31.8\end{array}$} & \multirow{2}{*}{$\begin{array}{l}9.6 \\
13.2\end{array}$} \\
\hline Male & $\begin{array}{l}1788 \\
(48.2)\end{array}$ & & & \\
\hline \multicolumn{5}{|l|}{ Food insecurity } \\
\hline No & \multirow[t]{2}{*}{$\begin{array}{l}1817 \\
(47.6)\end{array}$} & 43.8 & 25.2 & 9.1 \\
\hline Moderate & & 49.0 & 29.5 & 12.0 \\
\hline \multirow[t]{2}{*}{ Severe } & $\begin{array}{l}1680 \\
(43.5)\end{array}$ & 56.8 & 34.4 & 20.5 \\
\hline & \multicolumn{2}{|l|}{$322(8.8)$} & & \\
\hline \multicolumn{5}{|l|}{ Psychological problems } \\
\hline No close friends & $403(10.8)$ & 46.0 & 28.8 & 11.9 \\
\hline Lonely & $793(20.2)$ & 57.5 & 35.9 & 15.4 \\
\hline Anxiety & $575(14.6)$ & 57.7 & 39.3 & 19.2 \\
\hline Suicidal ideation & $981(25.0)$ & 56.6 & 34.1 & 15.7 \\
\hline Suicide plan & $854(21.4)$ & 60.2 & 36.7 & 15.5 \\
\hline Suicide attempt & $656(16.8)$ & 61.3 & 40.2 & 21.8 \\
\hline
\end{tabular}




\begin{tabular}{|c|c|c|c|c|}
\hline Current tobacco use & $384(10.1)$ & 77.9 & 60.3 & 35.5 \\
\hline Current cannabis use & $516(13.4)$ & 79.6 & 69.8 & 32.8 \\
\hline Ever amphetamines & $187(5.5)$ & 75.3 & 72.8 & 42.5 \\
\hline \multicolumn{5}{|l|}{ Social problems } \\
\hline School truancy & $889(22.0)$ & 61.5 & 47.7 & 23.6 \\
\hline Physically attacked & $\begin{array}{l}1064 \\
(28.7)\end{array}$ & 56.7 & 36.5 & 19.7 \\
\hline In physical fight & $\begin{array}{l}1235 \\
(33.2)\end{array}$ & 59.2 & 37.6 & 20.3 \\
\hline Injury & $\begin{array}{l}1589 \\
(45.9)\end{array}$ & 55.4 & 35.8 & 17.1 \\
\hline Multiple sexual partners & $979(24.2)$ & 68.8 & 54.3 & 21.7 \\
\hline Non-condom use & $669(17.5)$ & 66.6 & 50.1 & 18.4 \\
\hline \multicolumn{5}{|l|}{ Social support } \\
\hline $\begin{array}{l}\text { Peer support } \\
\text { (mostly/always) }\end{array}$ & $909(25.3)$ & 46.7 & 26.2 & 11.4 \\
\hline \multicolumn{5}{|l|}{ Parental/guardian support } \\
\hline $0-1$ & $\begin{array}{l}1732 \\
(46.6)\end{array}$ & 53.0 & 34.7 & 13.7 \\
\hline 2 & 100 & 46.5 & 25.1 & 11.0 \\
\hline $3-4$ & $986(28.2)$ & 36.4 & 18.5 & 6.2 \\
\hline
\end{tabular}

Table 2: Simple logistic regression with alcohol use outcomes 
Variable

Variable

Current alcohol use

OR $(95 \% \mathrm{CI})$
Ever drunk

OR $(95 \% \mathrm{Cl})$
Trouble from drinking

OR $(95 \% \mathrm{Cl})$

\section{Socio-demographics}

Country

$\begin{array}{clll}\text { Saint Lucia } & 1 \text { (Reference) } & 1 \text { (Reference) } & 1 \text { (Reference) } \\ \text { Saint Vincent/Grenadines } & 1.02(0.83,1.24) & 1.58(1.24,2.02)^{\star \star \star} & 1.68(1.26,2.25)^{\star \star \star}\end{array}$

Age (years)

$\begin{array}{llll}\leq 13 & 1 \text { (Reference) } & 1 \text { (Reference) } & 1 \text { (Reference) } \\ 14-15 & 1.52(1.16,2.00)^{\star \star} & 1.78(1.30,2.37)^{\star \star \star} & 1.41(0.91,2.17) \\ \geq 16 & 2.75(2.12,3.58)^{\star \star \star} & 3.87(2.90,5.16)^{\star \star \star} & 1.83(1.20,2.81)^{\star \star \star}\end{array}$

Gender

Female

1 (Reference)

1 (Reference)

1 (Reference)

Male

$1.02(0.88,1.17)$

$1.46(1.23,1.73)^{\star \star \star}$

$1.44(1.15,1.80)^{\star \star}$

Food insecurity

No

1 (Reference)

1 (Reference)

1 (Reference)

Moderate

$1.23(1.05,1.45)^{\star}$

$1.24(1.04,1.48)$

$1.36(1.04,1.78)$ *

Severe

$1.69(1.27,2.25)^{\star \star \star}$

$1.56(1.19,2.05)^{\star \star}$

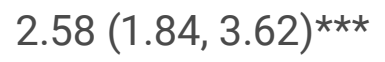

\section{Psychological problems}

\begin{tabular}{llll} 
No close friends & $0.95(0.76,1.19)$ & $1.06(0.83,1.34)$ & $1.07(0.74,1.56)$ \\
\hline Lonely & $1.69(1.36,2.10)^{\star \star \star}$ & $1.61(1.33,1.95)^{\star \star \star}$ & $1.61(1.23,2.09)^{\star \star \star}$ \\
\hline Anxiety & $1.65(1.36,2.01)^{\star \star \star}$ & $1.89(1.32,2.34)^{\star \star \star}$ & $2.20(1.67,2.89)^{\star \star \star}$ \\
\hline Suicidal ideation & $1.68(1.40,2.02)^{\star \star \star}$ & $1.54,1.29,1.84)^{\star \star \star}$ & $1.77(1.40,2.20)^{\star \star \star}$ \\
\hline Suicide plan & $1.98(1.65,2.38)^{\star \star \star}$ & $1.75(1.44,2.13)^{\star \star \star}$ & $1.75(1.35,2.26)^{\star \star \star}$ \\
\hline Suicide attempt & $1.99(1.61,2.46)^{\star \star \star}$ & $2.61(1.66,2.41)^{\star \star \star}$ & $2.75(2.07,3.66)^{\star \star \star}$ \\
\hline Current tobacco use & $4.54(3.29,6.34)^{\star \star \star}$ & $4.74(3.78,6.45)^{\star \star \star}$ & $5.93(4.33,8.13)^{\star \star \star}$ \\
\hline Current cannabis use & $5.56(4.21,7.33)^{\star \star \star}$ & $8.17(6.51,10.25)^{\star \star \star}$ & $6.15(4.54,8.34)^{\star \star \star}$ \\
\hline Ever amphetamine use & $3.68(2.39,5.68)^{\star \star \star}$ & $7.95(5.21,12.23)^{\star \star \star}$ & $7.33(4.56,11.77)^{\star \star \star}$ \\
\hline Social problems & & & \\
\hline School truancy & $2.13(1.78,2.57)^{\star \star \star}$ & $3.16(2.59,3.85)^{\star \star \star}$ & $3.75(2.94,4.79)^{\star \star \star}$
\end{tabular}




\begin{tabular}{|llll|}
\hline Physically attacked & $1.70(1.42,2.03)^{\star \star \star}$ & $1.78(1.53,2.08)^{\star \star \star}$ & $2.81(2.14,3.69)^{\star \star \star}$ \\
\hline In physical fight & $2.06(1.69,2.50)^{\star \star \star}$ & $2.09(1.70,2.35)^{\star \star \star}$ & $3.38(2.64,4.32)^{\star \star \star}$ \\
\hline Injury & $3.38(2.63,4.51)^{\star \star \star}$ & $2.13(1.78,2.53)^{\star \star \star}$ & $3.38(2.53,4.51)^{\star \star \star}$ \\
\hline Multiple sexual partners & $3.32(2.79,3.97)^{\star \star \star}$ & $5.11(4.17,6.26)^{\star \star \star}$ & $3.39(2.54,4.50)^{\star \star \star}$ \\
\hline Non-condom use & $2.64(2.12,3.29)^{\star \star \star}$ & $3.49(2.72,4.48)^{\star \star \star}$ & $2.39(1.79,3.18)^{\star \star \star}$ \\
\hline Social support & & & \\
\hline Peer support (mostly/always) & $0.99(0.81,1.20)$ & $0.90(0.73,1.10)$ & $1.04(0.80,1.36)$ \\
\hline Parental/guardian support & & & $1($ Reference $)$ \\
$0-1$ & $1($ Reference $)$ & $1($ Reference $)$ & $0.78(0.57,1.08)$ \\
2 & $0.77(0.65,0.92)^{\star \star}$ & $0.63(0.50,0.79)^{\star \star \star}$ & $0.42(0.31,0.19)^{\star \star \star}$ \\
\hline $3-4$ & $0.51(0.40,0.64)^{\star \star \star}$ & $0.50(0.34,0.54)^{\star \star *}$ & 0.42 \\
\hline
\end{tabular}

Table 3: Multiple logistic regression with alcohol use outcomes 


\begin{tabular}{|c|c|c|c|}
\hline Variable & Current alcohol use & Ever drunk & Trouble from drinking \\
\hline & AOR $(95 \% \mathrm{Cl})$ & AOR $(95 \% \mathrm{Cl})$ & AOR $(95 \% \mathrm{Cl})$ \\
\hline \multicolumn{4}{|l|}{ Socio-demographics } \\
\hline Country & - & & \\
\hline Saint Lucia & & 1 (Reference) & 1 (Reference) \\
\hline Saint Vincent/Grenadines & & $0.96(0.73,1.27)$ & $1.53(1.11,2.14)^{\star}$ \\
\hline \multicolumn{4}{|l|}{ Age (years) } \\
\hline$\leq 13$ & 1 (Reference) & 1 (Reference) & 1 (Reference) \\
\hline $14-15$ & $1.48(1.12,1.95)^{\star \star}$ & $1.54(1.08,2.19) \star$ & $1.25(0.73,2.17)$ \\
\hline$\geq 16$ & $2.82(2.06,3.86)^{\star \star \star}$ & $3.20(2.20,4.65)^{\star \star \star}$ & $1.16(0.62,2.16)$ \\
\hline Gender & - & & \\
\hline Female & & 1 (Reference) & 1 (Reference) \\
\hline Male & & $0.90(0.69,1.15)$ & $0.84(0.58,1.20)$ \\
\hline \multicolumn{4}{|l|}{ Food insecurity } \\
\hline No & 1 (Reference) & 1 (Reference) & 1 (Reference) \\
\hline Moderate & $1.01(0.80,1.28)$ & $1.15(0.93,1.43)$ & $1.27(0.88,1.84)$ \\
\hline Severe & $1.03(0.69,1.53)$ & $0.88(0.54,1.43)$ & $2.11(1.22,3.64)^{\star \star}$ \\
\hline \multicolumn{4}{|l|}{ Psychological problems } \\
\hline Lonely & $1.14(0.85,1.54)$ & $1.09(0.79,1.49)$ & $0.90(0.54,1.50)$ \\
\hline Anxiety & $1.05(0.79,1.40)$ & $1.36(0.95,1.95)$ & $1.40(0.94,2.09)$ \\
\hline Suicidal ideation & $0.90(0.62,1.29)$ & $0.96(0.68,1.35)$ & $1.49(1.00,2.22)^{\star}$ \\
\hline Suicide plan & $1.38(0.93,2.03)$ & $1.27(0.87,1.85)$ & $0.60(0.34,1.06)$ \\
\hline Suicide attempt & $1.11(0.75,1.64)$ & $1.20(0.80,1.79)$ & $1.12(0.61,2.06)$ \\
\hline Current tobacco use & $2.06(1.25,3.40)^{\star \star}$ & $2.60(1.58,4.18)^{\star \star \star}$ & $2.02(1.20,3.39)^{\star \star}$ \\
\hline Current cannabis use & $2.53(1.73,3.69)^{\star \star \star}$ & $3.46(2.49,4.94)^{\star \star \star}$ & $2.07(1.32,3.25)^{\star \star}$ \\
\hline Ever amphetamine use & $2.20(0.95,5.10)$ & $2.97(1.16,7.60) \star$ & $2.01(0.93,4.35)$ \\
\hline \multicolumn{4}{|l|}{ Social problems } \\
\hline School truancy & $1.35(1.06,1.73)^{\star}$ & $1.89(1.42,2.50)^{\star \star \star}$ & $2.07(1.49,2.86)^{\star \star \star}$ \\
\hline Physically attacked & $1.05(0.81,1.35)$ & $1.09(0.84,1.40)$ & $1.22(0.82,1.81)$ \\
\hline
\end{tabular}




\begin{tabular}{|llll|}
\hline In physical fight & $1.87(1.44,2.43)^{\star \star \star}$ & $1.53(1.20,1.95)^{\star \star \star}$ & $2.12(1.44,3.11)^{\star \star \star}$ \\
\hline Injury & $1.42(1.14,1.76)^{\star \star}$ & $1.51(1.18,1.94)^{\star \star \star}$ & $1.49(1.01,2.21)^{\star}$ \\
\hline Multiple sexual partners & $1.90(1.49,2.41)^{\star \star \star}$ & $2.33(1.69,3.20)^{\star \star \star}$ & $2.03(1.34,3.07)^{\star \star \star}$ \\
\hline Non-condom use & $1.10(0.82,1.47)$ & $1.22(0.89,1.67)$ & $1.10(0.75,1.62)$ \\
\hline Social support & & & \\
\hline Parental/guardian support & & & \\
$0-1$ & 1 (Reference) & 1 (Reference) & 1 (Reference) \\
2 & $0.90(0.71,1.14)$ & $0.70(0.51,0.94)^{\star}$ & $0.86(0.57,1.31)$ \\
$3-4$ & $0.71(0.57,0.88)^{\star \star}$ & $0.66(0.49,0.90)^{\star \star}$ & $0.59(0.40,0.89)^{\star}$ \\
\hline
\end{tabular}

AOR=Adjusted Odds Ratio; $\mathrm{Cl}=$ Confidence Interval

\section{Supplementary Files}

This is a list of supplementary files associated with this preprint. Click to download.

- Appendix1.docx 